\title{
Percurso de vida dos ex-jogadores do Clube Desportivo Matchedje de Maputo
}

\author{
Lifestyle of the ex-players of the Matchedje Sports Club of Maputo \\ Curso de vida de exjugadores del Clube Deportivo Matchedje de Maputo \\ Pedro antónio Pessula ${ }^{1}$; Bernardo Manjate ${ }^{2}$; Madalena Bive ${ }^{3}$ \\ Universidade Pedagógica de Maputo, UP, Maputo, Moçambique \\ Clube Matchedje de Maputo, Maputo, MoçaMbiQue \\ Universidade Púnguè, UniPúnguè, Manica, MoçAMbiQue \\ RESUMO
}

\begin{abstract}
O presente trabalho visa descrever as histórias de vida de ex-futebolistas do Clube Matchedje de Maputo. Para tal foram entrevistados quatro ex-jogadores deste clube. Para este trabalho entrevistaram-se os jogadores de acordo com um guião de entrevista previamente elaborado. Os resultados revelaram que a maioria dos exjogadores é oriunda das cidades e de famílias humildes que não tinham condições mínimas para lhes garantir a continuação dos estudos até ao secundário. Outrossim, revelam que encerraram as suas carreiras na faixa etária entre 20 e 36 anos e tiveram como principal causa as lesões e a idade. No fim da carreira muitos jogadores tiveram de garantir o seu próprio sustento e das suas famílias, não lhes sobrando tempo suficiente para outras atividades como, por exemplo, a continuação de estudos com que se poderiam valorizar profissionalmente. Apesar disso, alguns continuam ligados ao futebol como treinadores dos escalões de formação a despeito dos baixos salários.
\end{abstract}

Palavras-chave: Histórias de Vida. Ex-Jogadores. Futebol.

\begin{abstract}
The present work aims to describe the life histories of the ex-soccer players of the Matchedje Club in Maputo. The study interviewed four ex-soccer players who gave their contribution during the peak of their careers. The instrument used was an interview script administered to ex-players. The results revealed that more ex-players come from cities and from humble families who had the minimum conditions to guarantee them continuation of studies until the secondary. At the end of the career many players have to ensure their own livelihood and of their families not leaving enough time for other activities. In addition, they show that they waxed their careers between 20 to 36 years old, most of them with injuries and others they reveal to continue embracing to the soccer like training trainers in spite of the low salaries.
\end{abstract}

Keywords: Stories. Ex-Players. Soccer.

\section{RESUMEN}

El presente trabajo tiene como objetivo describir las historias de vida de los exfutbolistas del Club Matchedje de Maputo. Para ello, se entrevistó a cuatro exjugadores que contribuyeron durante la cumbre de sus carreras. El instrumento utilizado fue una guía de entrevista administrada a exjugadores. Los resultados revelaron que un mayor número de exjugadores provienen de las ciudades y de familias humildes que no tenían las condiciones mínimas para garantizarles continuar sus estudios hasta el bachillerato. Al final de su carrera, muchos jugadores tuvieron que garantizar su propio sustento y el de sus familias, no disponiendo de tiempo suficiente para otras actividades como continuar sus estudios. Además, revelan que terminaron su carrera en el grupo de edad entre 20 y 36 años y tenían las lesiones y la edad como causa principal. Algunos siguen apegados al fútbol como entrenadores en las categorías inferiores a pesar de los bajos salarios.

Palabras clave: Historias de Vida. Exjugadores. Fútbol.

\footnotetext{
${ }^{1}$ Docente da UP. E-mail: pessula.fefd@ gmail.com. ORCID: http://orcid.org/0000-0002-3727-262X.

2 Primeiro Vogal de Direção do Clube Matchedje de Maputo. E-mail: salvadormaximiano91@gmail.com. ORCID: http://orcid.org/0000-0002-4354-7052.

3 Docente da UniPúnguè. E-mail: madalenatirano15@gmail.com. ORCID: http://orcid.org/0000-0003-0622$\underline{2053}$.
} 


\section{INTRODUÇÃO}

Sem prejuízo do reconhecimento das especificidades da prática futebolística nos diversos contextos sociais, comecemos por referir alguns aspectos básicos relativos ao futebol e à carreira do futebolista.

O futebol é a maior e mais popular modalidade desportiva, daí a sua designação de desporto-rei em grande número de países. O futebol exerce um forte poder de fascínio sobre milhões de pessoas. Segundo Kunz (2007), o censo realizado em 2006 apurou a existência de cerca de 265 milhões de praticantes de futebol em todo o mundo, dos quais 113 mil eram profissionais.

Uma partida de futebol, conforme Bento (2013, p. 47),

[...] é pretexto para as mais diversas finalidades e instrumentalizações. Dela disseminam- se desígnios inimagináveis para algumas mentes, havendo nela, pelo menos, dois jogos simultâneos: o dos jogadores e o dos adeptos. Dito de outro modo, o desempenho dos jogadores é ocasião para os adeptos jogarem o seu jogo que se joga nas bancadas e se reflecte nas dinâmicas políticas e sociais.

Neste contexto, os jogadores de futebol além de cumprir com o que os treinadores mandam fazer, são pressionados pelos adeptos para render mais em busca da vitória e, muitas das vezes, são vaiados e criticados quando os resultados não aparecem.

São esses jogadores de futebol, praticantes que se dedicam ao desporto integralmente ou parcialmente, que são objeto do nosso estudo. Os jogadores de futebol a tempo inteiro são contratados como trabalhadores por clubes com a finalidade de produzir resultados desportivos e econômicos como foi o caso do Clube Desportivo Matchedje de Maputo.

O jogador de futebol, geralmente, entra na vida do desporto ainda na fase de adolescência e desde esse momento exige-se-lhe, para o seu sucesso e dos clubes que representa, um grande investimento no tempo, não lhe sobrando, na maior parte das vezes, nem tempo, nem disposição para as suas obrigações estudantis e de preparação para o período pós-carreira.

Brandão (2004) considera que o sonho de muitos jovens jogadores de futebol é obter sucesso nacional e internacional, já que esta conquista significa auferir elevados valores monetários e ter notoriedade. Amaral, Thiengo e Silva Oliveira (2007) acrescentam que estes jovens são seduzidos por uma vida social de status e de independência financeira, encarando a carreira de jogador de futebol profissional como uma das mais promissoras.

O termo da carreira desportiva significa a transição para outra fase da vida, acompanhada por concomitantes mudanças nas características psicológicas e sociais do atleta e, por vezes, da necessidade de recursos para lidar com as dificuldades desse momento da trajetória da vida. Cada fase da vida requer exigências específicas e ajustamentos nas esferas ocupacional, financeira, social e psicológica do atleta e, fundamentalmente, sempre será necessário o esforço pessoal para a adaptação à nova fase. Algumas transições após o término de carreira podem ser positivas, sobretudo quando existem precondições para a adaptação a novas circunstâncias sócioprofissionais (AGRESTA; BRANDÃO; BARROS NETO, 2008a).

Agresta, Brandão e Barros Neto (2008a) afirmam que, com o encerramento da carreira futebolística, os ex-jogadores precisam se ajustar a sua nova vida, tanto no campo financeiro, como no psicológico e social, até porque implica uma mudança de 
comportamentos e de valores em relação ao mundo em que os ex-futebolistas vinham vivendo.

Note-se, nem todas as "maravilhas" relacionadas ao futebol profissional são reais, ou para todos, porque há casos de sucesso e outros de insucesso. Segundo Guimarães (2017), muitas carreiras são abortadas precocemente pela falta de oportunidade de assinar bons contratos. Ou, também sucede, as carreiras são prolongadas com contratos precários devido à idade e porque o jogador não tem outra fonte de renda.

Ao fim da carreira, alguns ex-jogadores procuram outras formas de ocupação como estratégias de sobrevivência. No estado da Paraíba, Brasil, por exemplo, o comércio é uma das ocupações, porque, mesmo sendo de menor retorno financeiro, esta possibilidade de inserção no mercado é pensada como uma boa alternativa, principalmente pela menor exigência de uma formação profissional específica (GUIMARÃES, 2017).

Outros ex-futebolistas, segundo Marco e Luiz Filho (2013), em Santa Catarina, Brasil, encaram dificuldades no seu quotidiano após o término das suas carreiras no tocante à sua inserção social e profissional, dificuldades associadas ao rápido desenvolvimento dos acontecimentos que não foram acompanhados por uma preparação adequada, quer a nível financeiro, quer a nível acadêmico na projeção do futuro.

$\mathrm{O}$ fato de ex-jogadores encararem dificuldades para se inserir social e profissionalmente após o termo de suas carreiras deve-se à falta de preparação para enfrentar o momento pós-carreira. Marco; Luiz Filho (2013) consideram que a falta de escolaridade, o afastamento da família, a falta de formação e de informação são os principais motivos que os levaram a não planear suas vidas para o futuro, por exemplo, através de investimentos a curto, médio e longo prazo.

Em função de alguns estudos, são apontadas como causas de encerramento da carreira de futebolista: (i) problemas de lesões e saúde; (ii) falta de estrutura e organização dos clubes; (iii) baixos salários; (iv) falta de profissionalismo dos dirigentes, empresários e técnicos; (v) falta de estabilidade na profissão; (vi) distância e relacionamento com a família; (vii) cansaço físico e idade avançada; (viii) declínio dos resultados/motivação; e (ix) a corrupção (AMARAL; THIENGO; SILVA OLIVEIRA, 2007; AGRESTA; BRANDÃO; BARROS NETO, 2008b; MARCO; LUIZ FILHO, 2013; RUNGO, 2014).

Após uma breve resenha da literatura passamos a abordar a carreira de futebolista no contexto moçambicano. $O$ futebol é a modalidade mais movimentada/praticada pela maioria da população e pratica-se em variadíssimos locais como, por exemplo, ruas, campos desnivelados até, naturalmente, em campos oficiais.

O futebol movimenta elevados valores monetários, mormente na contratação de treinadores e jogadores, incluindo estrangeiros, diferentemente do que sucede nas demais modalidades. Geralmente, a carreira de futebolista começa aos 10 anos nas principais cidades do país (Maputo, Beira, Quelimane e Nampula) e termina por volta dos 34 anos.

Rungo (2014) observou no seu estudo que a maioria dos ex-praticantes de futebol provém das zonas suburbanas e de famílias modestas, as quais muito dificilmente poderiam ter condições para lhes garantir a continuação de estudos na chamada idade escolar. Por isso, a estes jovens futebolistas cumpre-lhes garantir o seu próprio sustento e das suas famílias, não lhes sobrando tempo para outras atividades. Outrossim, a maioria encerrou as suas carreiras de forma brusca na faixa dos 28 a 30 anos por lesão, corrupção, baixos salários, decréscimo da sua performance e ausência de perspectivas de melhores performances desportivas e de acréscimo de proventos. 
Mesmo se pautada por dificuldades, em parte relacionáveis com as dificuldades econômicas do país, a carreira futebolística relevou-se como um mecanismo de mobilidade social. Com efeito, depois do término das suas carreiras, a maior parte dos ex-jogadores voltou à escola, existindo muitos a frequentar o ensino superior. As causas do não planeamento da carreira apontadas em Moçambique são a falta de informação; o abandono dos estudos e permanência longe da família e, por fim, o início precoce da carreira (RUNGO, 2014).

Após encerrar as suas carreiras de jogadores de futebol em Moçambique, grande parte abandona completamente o meio desportivo. Outros ainda seguem participando do quotidiano do desporto, sendo que, a maioria como treinadores, alguns como árbitros e poucos como gestores desportivos.

Como referimos, grande parte dos treinadores em Moçambique são exfutebolistas, tais os casos de João Chissano ${ }^{4}$ que assumiu o cargo de treinador em várias equipes e até na seleção nacional; de Zainadine Mulungo ${ }^{5}$ (ex-Maxaquene) que vem treinando várias equipes; Chiquinho $\operatorname{Conde}^{6}$ que já foi campeão nacional como treinador do Ferroviário de Maputo e da União Desportiva do Songo; de Artur Semedo ${ }^{7}$, que, depois de passar pelo futebol português como jogador, treinou vários clubes moçambicanos, tendo sido campeão nacional pelo Desportivo de Maputo, Ferroviário de Maputo, Liga Desportiva de Maputo, União Desportiva do Songo; e de Dário Monteiro $^{8}$ que treina as seleções nacionais sub-20 e sub-17, treinou a Liga Desportiva de Maputo, e Desportivo de Maputo e os sub-23 da Académica de Coimbra. Estes são exemplos raros de ex-futebolistas bem-sucedidos.

No entanto, entendemos que o fato de ter sido bom jogador de futebol e participar em alguns cursos não é suficiente para ser treinador. Julgamos que uma formação acadêmica na área de Educação Física e Desporto fornece bases para conduzir bem os homens na carreira de futebolistas. A formação do nível médio ou superior fornece subsídios sobre a fisiologia do esforço, psicologia do desporto, metodologia de treino, nutrição, entre outras, o que permitirá ao treinador conhecer o ser humano que vai orientando.

Embora não ocorra só em Moçambique, vários atletas ${ }^{9}$ do país perderam a vida depois de terminar as suas carreiras desportivas ao se envolverem no consumo de bebidas alcoólicas de fabrico caseiro, como, por exemplo, o thothotho ${ }^{10}$, comprometendo a saúde e o seu estado físico, um percurso associado a uma presumível perda de autoestima. Daí surge a inquietação: Como é que os ex-futebolistas vivem o fim da carreira desportiva junto às suas famílias e qual o apoio recebido para o póscarreira futebolística?

Partindo desta constatação e pelo fato de muito pouco se escrever sobre esta temática em Moçambique, definimos como objetivo narrar e refletir sobre as histórias de vida de ex-futebolistas do Clube Desportivo do Matchedje. A escolha deste clube

\footnotetext{
${ }^{4}$ Jogou no Ferroviário de Maputo, Costa do Sol e na Seleção Nacional.

${ }^{5}$ Jogou no Desportivo de Maputo, Maxaquene e na Seleção Nacional.

6 Jogou no Ferroviário da Beira, Maxaquene em Moçambique, Belenenses, Sporting e Setúbal em Portugal, entre outros clubes que representou. Foi capitão da Seleção Nacional de Futebol de Moçambique. Atualmente é treinador do sub-23 de Setúbal em Portugal.

${ }^{7}$ Jogou no Costa do Sol em Moçambique, Benfica de Lisboa, Marítimo em Portugal, entre outros clubes. Foi capitão da Seleção Nacional de Futebol de Moçambique.

8 Jogou no Desportivo de Maputo e Liga Desportiva de Maputo em Moçambique, Académica de Coimbra, em Portugal, onde foi capitão, Jomo Cosmos, da África do Sul. Foi capitão da Seleção Nacional de Futebol de Moçambique.

${ }^{9}$ Por questões éticas não se mencionam os seus nomes.

${ }^{10}$ Bebida tradicional fabricada a partir da destilação de cana-de-açúcar ou caju.
} 
deve-se ao fato de na década 90 ter sido o que recebia apoio diretamente do Presidente da República.

\section{MATERIAL E MÉTODOS}

Para este artigo, realizamos uma pesquisa documental e narrativa com um delineamento qualitativo. A pesquisa documental caracteriza-se pela recolha de documentos, escritos ou não, constituintes do que se denomina de fontes primárias. Estas podem ser feitas no momento em que o fato ou fenômeno ocorre ou depois (MARCONI; LAKATOS, 2003). Esta pesquisa foi usada para compor a história do Clube Desportivo Matchedje.

As narrativas e histórias de vidas, segundo Leão (2016), são fontes valiosas que estão presentes em vários momentos da pesquisa acadêmica. A este propósito, Rubio (2014, p. 115) considera que as narrativas biográficas são entendidas como "[...] discursos individuais que oferecem uma compreensão do sujeito que narra, do mundo e das próprias experiências acumuladas na trajetória da existência".

Sobre a sistematização das narrativas, Pineau (1999) apresenta as seguintes categorias: biografia, autobiografia, relatos orais e histórias de vida. (i) Biografia é a escrita da trajetória de vida do outro, identificando-se com um certo distanciamento entre o participante e o investigador com o objetivo de construir um conhecimento objetivo; nalguns casos, o distanciamento não existe e, por vezes, não se evita alguma aproximação com o biografado; (ii) autobiografia é a escrita acerca de si, da sua própria trajetória, colocando-se o sujeito numa situação de ator e autor de suas experiências; por regra, não há mediação de outros na produção dessa biografia. As autobiografias centram-se na singularidade e subjetividade dos envolvidos; (iii) os relatos orais são as narrativas que cada indivíduo apresenta a cerca de si mesmo, sem que as escreva, podendo tais narrativas ser usadas como fonte de pesquisa; e (iv) as histórias de vida são uma forma de auto-compreensão das pessoas que somos, das aprendizagens vivenciadas e eternizadas em toda nossa trajetória de vida.

Neste estudo usamos os relatos orais e as histórias de vida para narrarmos o percurso de vida de ex-jogadores de futebol do Clube Matchedje de Maputo. Assim, constituíram sujeitos da nossa pesquisa quatro ex-jogadores de futebol deste Clube com informação detalhada adiante.

A participação destes ex-jogadores, que evoluíram no clube entre 1980 e 1990, foi de forma voluntária. Já outros não se disponibilizaram a colaborar nesta pesquisa. Para a recolha de dados foi elaborado um documento de pedido de consentimento para o ingresso em instalações desportivas do Clube Matchedje e obter dados deste clube. Após o contato inicial com os ex-jogadores foi-lhes apresentado e explicado o conteúdo da entrevista e o termo de consentimento livre, tendo sido esclarecidas as dúvidas relativas às questões abordadas no guião da entrevista. Gravamos as entrevistas que posteriormente transcrevemos para posterior análise.

Os dados recolhidos são descritivos e tiveram como maior preocupação indiciar com dados empíricos o processo pelo qual se desenvolve a carreira dos jogadores de futebol em Moçambique. Durante o processo da pesquisa foi dada maior atenção ao significado que as pessoas atribuem às coisas e à sua vida, procurando captar a perspectiva dos participantes (LÜDKE; ANDRÉ, 2013).

Para análise dos dados recorremos à descrição dos fatos relatados pelos exjogadores sobre a sua infância e adolescência, a sua carreira futebolística e sobre o período pós-carreira. Os dados das entrevistas foram analisados a partir da descrição das 
falas dos ex-jogadores com enfoque nas suas percepções sobre a sua carreira, percepções agrupadas em três focos temáticos: (i) infância e adolescência dos entrevistados; (ii) carreira futebolística; (iii) e pós- carreira.

\section{O FUTEBOL EM MOÇAMBIQUE}

O futebol foi introduzido em África e, consequentemente, em Moçambique, por múltiplos agentes com distintos interesses. É o caso de grandes companhias que patrocinavam atividades desportivas, procurando controlar assim as relações laborais. À disseminação do desporto também não foi alheio o esforço missionário, que visava a educação, a disciplina e a integração comunitária dos nativos de Moçambique (DOMINGOS, 2006).

Outras razões que influenciaram a disseminação do desporto em Moçambique, segundo Domingos (2006), foram a dinâmica associativa dos colonos, caracterizada por uma ativa componente desportiva e os fluxos migratórios, de que o movimento maciço de trabalhadores moçambicanos para a África do Sul e para a Rodésia é um exemplo evidente. A própria dinâmica econômica, impulsionada, sobretudo a partir da viragem para o século XX, pelo crescimento dos meios de transporte, originou uma maior mobilidade dos indivíduos entre as colônias e a metrópole.

Domingos (2006, p. 403) afirma que

[...] a organização desportiva desenvolvida em Moçambique sob domínio colonial português reflectiu de forma particular as clivagens sociais que caracterizavam este espaço colonial. A introdução dos desportos modernos beneficiou do crescimento das principais cidades, designadamente de Lourenço Marques, nova capital do território em 1898. A sua posição estratégica na economia regional sul-africana, alimentada pela descoberta de ouro em 1873 na região do Transval, levou à intensificação da exploração do porto à construção do caminho-de-ferro que ligava o território aos países vizinhos, isto explica a expansão do clube Ferroviário por todo país.

Acrescenta Domingos (2014) que em 1923, na então Lourenço Marques, foi fundada uma associação de futebol representativa do associativismo desportivo dos colonos, a Associação de Futebol de Lourenço Marques (AFLM). No ano seguinte, no subúrbio, na chamada "cidade de caniço", foi fundada a Associação de Futebol Africana (AFA). A AFA organizava as competições envolvendo população negra e indígena, cujos clubes não podiam inscrever-se na AFLM, em consonância, de resto, com a negação do direito associativo aos chamados "indígenas". As equipes dos subúrbios não jogavam com as da AFLM e, até a década de 1960, o número de jogadores que transitou da AFA para os chamados "clubes da baixa" da cidade foi muito exíguo. O contexto após o fim do indigenato, em 1961, deu origem a uma maior abertura e mobilidade, num tempo de grande pressão internacional sobre o império português, quando entrementes se iniciara também a guerra colonial.

O capitão português Ismael Mário Jorge ${ }^{11}$ foi um dos pioneiros a escrever sobre o desporto no Moçambique colonial. O capitão Ismael salientava que a atividade da AFA era a de organizar competições com a participação de mais de uma dezena de

\footnotetext{
${ }^{11}$ Não foi um caso único, porquanto vários militares se desdobraram no apoio ao desenvolvimento das atividades desportivas, o capitão de infantaria Ismael Mário Jorge foi uma figura importante no desenvolvimento do desporto em Moçambique: foi professor no Liceu 5 de Outubro, chefe dos escuteiros, presidente da Junta de Salvação Pública e dirigente da Associação de Futebol de Lourenço Marques.
} 
clubes das zonas suburbanas. A AFA adaptava as regras e regulamentos típicos das congêneres de origem europeia, em conformidade, aliás, com a padronização das regras do futebol em vias de se tornarem universais. Apesar de os estatutos da AFA só terem sido aprovados em 1934, a associação funcionava desde a década de 1920, período caracterizado por um forte incremento do associativismo africano (DOMINGOS, 2006).

Domingos (2014) afirma que os jogadores das equipes filiadas na AFA deveriam atuar equipados com botas, meias, calções e camisolas. Os símbolos e as cores das equipes ajudavam a revelar as várias comunidades urbanas associadas aos clubes. Identificavam-se aqueles que pertenciam ao grupo de relações mais próximas e, simultaneamente, e talvez de forma mais significativa, aqueles que pertenciam a outros grupos, mas que participavam também em cerimônias locais.

Antes e à margem de um enquadramento institucional, o futebol ter-se-á desenvolvido de forma espontânea por ter sido jogado nas ruas, nos bairros, não se sabendo se por equipes mistas ou racialmente separadas (DOMINGOS 2014).

\begin{abstract}
A sua expansão pelo território terá sido rápida, como comprova uma crónica que O Brado Africano publicou em 1939 (21/1, p. 5) sobre a vida desportiva no distrito de Inhambane: «O futebol, aqui, como de resto em toda a parte, é o desporto-rei por excelência. É o desporto que se pratica em maior escala, e é ver por essas estradas que atravessam o Distrito ${ }^{12}$ vários campos de futebol (?) com árvores no meio e dois bambus espetados no solo e atravessados por um terceiro a servirem de balizas!» (DOMINGOS, 2006, p. 406).
\end{abstract}

Na década de 1950, o poeta e jornalista moçambicano José Craveirinha publicou um conjunto de artigos nos jornais sobre a tradição do futebol suburbano. Craveirinha dava relevo a um conjunto de gestos habituais nos desempenhos dos jogadores, gestos que, pela sua importância, mereceriam designações específicas. Tais gestos revelavam algumas das possibilidades de recriação do jogo de futebol pelos nativos. Portanto, os corpos dos jogadores respondiam a outros hábitos e costumes decorrentes da sua experiência social mais alargada do que a definida pelas tendencialmente padronizadas regras do futebol (DOMINGOS, 2014).

Também em Moçambique, nem todos acolhiam favoravelmente o futebol. O articulista José Manuel ${ }^{13}$ escreveu, em 1953, seis crônicas intituladas "A mocidade e o futebol" (DOMINGOS, 2006). Nessas crônicas José Manuel defendia que a valorização do indivíduo africano estava precisamente a ser travada pela

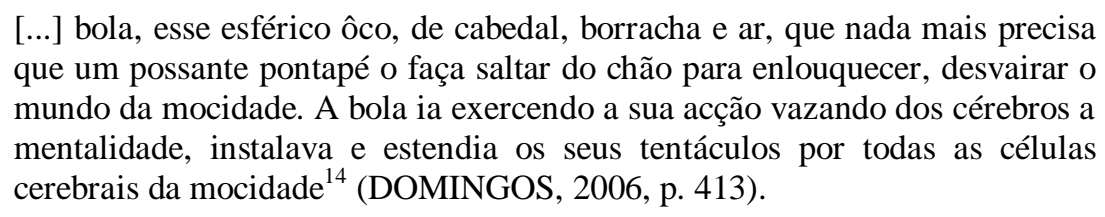

Para Manuel, a crítica aos jovens da altura era contraposta ao elogio de gerações precedentes porque anteriormente

\footnotetext{
${ }^{12} \mathrm{Na}$ nova divisão administrativa delineada depois da independência de Moçambique, o distrito passou a designar-se província.

13 Muito provavelmente, será um africano que pertenceu à Associação Africana da Colónia de Moçambique, tendo sido também presidente do Centro Associativo dos Negros da Colónia de Moçambique, nome pelo qual ficou denominada, depois de 1938, uma importante coletividade africana, o Instituto Negrófilo de Lourenço Marques (DOMINGOS, 2006).

${ }^{14}$ Crônica de José Manuel publicado no jornal O Brado Africano de 8 de Agosto de 1953 (DOMINGOS, 2006).
} 
[...] moços surgiram a elevar bem alto o valor intelectual do negro, a demonstrar, desmentindo velhos conceitos errados, da sua inferioridade cerebral, conceitos afirmados por intelectuais que do negro, de bom só lhe acham a força hercúlea dos braços para o trabalho e não curam em saber que além dos músculos fortes o seu corpo alberga, também, um predicado com que Deus, além da matéria, dotou todo o ser humano, sem distinção de cor da epiderme - o Espírito ${ }^{15}$ (DOMINGOS, 2006, p. 413).

O futebol era músculo e a força do músculo não significava outra coisa senão a preservação da dimensão corporal do africano, na definição do colonialista, o trabalhador braçal. Ora, para os que duvidavam das virtudes do futebol, este era ainda pior do que o trabalho, por não ser produtivo ${ }^{16}$. O jogo não contribuía para qualquer elevação espiritual, ao contrário da leitura ou da música, atividades mais consentâneas com "[...] o esforço civilizador de Portugal nestas paragens orientais de África" "17 (DOMINGOS, 2006, p. 413).

Esta visão não era estranha a uma concepção global de civilização, também aceita por parte das elites africanas, razão pela qual estas se empenhavam no propósito de reivindicação de direitos face ao poder colonial.

A elite encontrava-se perante um dilema: de acordo com a referida visão global da civilização, admitida a divisão racionalista ocidental entre corpo e mente (razão), retirava-se do corpo qualquer faculdade inteligente. Ao futebol não eram reconhecidas qualidades civilizadoras. Em todo o caso, e tal como acontecia por toda a parte, o futebol interessava a cada vez mais a um crescente número de africanos.

\section{História do Clube MATChEDJE}

Em 1964, no Centro de Preparação Político Militar de Kongwa, Tanzânia, nasce a primeira equipe de futebol, denominada de Equipa dos Guerrilheiros. Com a Independência Nacional, a sede da agremiação passou para Boane, com nova denominação, a saber, a equipe das Forças Populares de Libertação de Moçambique (FPLM) e, em 25 de Junho de 1979, foi batizada de Clube Desportivo Matchedje.

Matchedje é nome de uma localidade do distrito de Sanga, na província nortenha do Niassa, Moçambique, com sede na localidade de Malulu. O distrito de Sanga tem como limites a oeste, o distrito do Lago; a sul, o distrito de Chimbonila; a leste, os distritos de Muembe e Mavago; e a norte com a República da Tanzânia. Foi na localidade de Matchedje que se realizou o II Congresso da Frente de Libertação de Moçambique (FRELIMO) sob a liderança de Eduardo Mondlane que foi o primeiro presidente da organização.

O Clube Desportivo do Matchedje é uma associação de caráter educativo, cultural e desportivo sem fins políticos, fundado em 25 de Junho de 1979 na cidade de Maputo. É o legítimo sucessor da equipe das Forças Populares de Libertação de Moçambique (FPLM) conforme narramos a seguir.

A equipe das FPLM, formada por jovens militares selecionados no Centro de Preparação Político Militar de Boane, participou num jogo de futebol com a seleção de

\footnotetext{
${ }^{15}$ Crônica de José Manuel publicado no jornal O Brado Africano de 15 de Agosto de 1953 (DOMINGOS, 2006).

${ }^{16}$ José Manual "[...] preocupava-se ainda com a «apreciável redução na produção, devido a constantes interrupções de trabalho para atender e replicar a segundos ou terceiros em assuntos da bola...» (O Brado Africano, 3-10-53: 2)" (DOMINGOS, 2006, p. 413).

${ }^{17}$ Crônica de José Manuel publicado no jornal O Brado Africano de 26 de Setembro de 1953 (DOMINGOS, 2006).
} 
futebol de trabalhadores da ex-Lourenço Marques no dia 25 de Setembro de 1975. O jogo realizou-se no Estádio da Machava, a que assistiram o Presidente da República, Samora Moisés Machel, e membros seniores do partido FRELIMO. Depois do jogo, o presidente, orientou que esta equipe fosse transferida para o quartel do ex-Batalhão 18, com objetivo de participar em jogos oficiais. É esta equipe que dá origem ao pelotão dos futebolistas, o qual mais tarde se filiou na Comissão de Futebol Recreativo de Maputo com o nome das F.P.L.M.

Em 1976 sagra-se campeão de futebol de trabalhadores, adquirindo o direito de participar no futebol federado com a sua filiação em 1977 na Associação de Futebol da Cidade de Maputo. Em 1979 ganha o campeonato da $2^{\text {a }}$ divisão, ascendendo à $1^{\text {a }}$ divisão no ano seguinte, 1980, já com o nome de Clube Desportivo Matchedje (CDM).

Desde a sua fundação, o clube guiou-se sempre pela disciplina militar. No entanto, em 1982 começa o recrutamento compulsivo de jogadores que se destacavam em outras equipes para cumprir o Serviço Militar Obrigatório. Esta seleção era realizada por oficiais superiores das Forças Armadas de Moçambique sem o envolvimento de nenhum treinador da equipe.

Os recrutados eram treinados militarmente no período de seis meses, passando depois para a equipe de futebol. De referir que durante a época desportiva, de manhã, os jogadores treinavam futebol e, à tarde, devotavam-se aos desempenhos militares, o que também acontecia nos tempos de defeso. Apesar de serem recrutados, posteriormente assinavam contratos com o clube o qual disponibilizava uma casa e um salário superior ao oferecido pela maior parte dos clubes moçambicanos, ou seja, boas regalias, atentos os constrangimentos econômicos dos anos pós-independência.

Esta estratégia, para além de fortalecer a equipe de futebol do clube, visava também, enfraquecer as equipes adversárias, proporcionando condições impossíveis para os demais clubes. É nesta fase que o Clube Matchedje se sagra campeão da $1^{\text {a }}$ divisão da cidade de Maputo e ascende à divisão nacional de futebol em 1984.

Dos vários jogadores recrutados para o CDM, destacam-se Filipe Chissequere (Ferroviário da Beira), Evans Npomberah (Namutequeliua), João Alves Onofre (Palmeiras de Quelimane), Nicolau de Sousa-Nico (Textil do Pungué), Manuel José Sete-Ze Manel (Têxtil de Pungué), Zacarias Osman (Costa do Sol), Carlos Alberto Baptista-Betinho (Palmeiras da Beira), Faruk Taquidir (Sporting e Ferroviário de Quelimane), Álvaro Matine (Costa do Sol e Académica de Maputo), Elcídio Conde (Ferroviário da Beira), Nacir Armando (Ressano Garcia), Amade Chababe Amade (Associação Desportiva de Pemba, Desportivo de Maputo), João Carlos Patrício-Maló (Maputo), Emanuel Matola-Nana (Académica de Maputo), Jerónimo Nhanombe (Desportivo de Maputo), Augusto Mussane (Estrela Vermelha de Maputo), entre outros, que faziam parte da seleção nacional de futebol de Moçambique.

É com esta equipe que o Clube Desportivo Matchedje se sagra campeão nacional de futebol em 1987 e, no ano seguinte, consegue alcançar as quartas-de-final da Taça dos Clubes Campeões de África. Em 1990, sagra-se pela segunda vez campeão nacional e, ao mesmo tempo, vencedor da taça de Moçambique.

O contrato dos jogadores do CDM terminava quando eles não pudessem render mais como futebolistas, passando então para os quadros técnicos do clube. Simultaneamente o Serviço Militar Obrigatório terminava com o fím da carreira e passavam a reserva. Os jogadores com mau comportamento ${ }^{18}$ eram dispensados para outros clubes e perdiam todas as regalias do CDM.

\footnotetext{
${ }^{18} \mathrm{O}$ clube considerava mau comportamento a ausência nos trabalhos indicados pelo clube, ausência nos treinos, consumo excessivo de álcool.
} 
Com as mudanças políticas verificadas no país em 1992, esta prática de lograr os melhores jogadores por via da conscrição militar já não encontrava espaço. Forçado a prescindir do suporte institucional, o clube sujeitou-se a inserir-se na sociedade para prosseguir a sua atividade. Neste âmbito, com uma nova filosofia, o clube aglutinou para além dos militares, jogadores civis, de modo a organizar e a lograr o crescimento do clube, com vista a fazer face às exigências da prática desportiva e, mais concretamente, futebolística numa economia de mercado.

Dentro do quadro da nova filosofia, conforme as mudanças políticas ocorridas desde 1992, em assembleia ordinária no dia 30 de Março de 2001 foram aprovados os novos estatutos do Clube Desportivo Matchedje, que foram publicados no Boletim da República, n. 41, de 19 de Outubro de 2010 (MOÇAMBIQUE, 2010). O clube passou a usar a sigla CDM, com a sua sede na cidade de Maputo. Segundo os estatutos, "O CDM tem a sua sede na cidade de Maputo, podendo ter delegações e outras formas de representação dentro e fora do país de acordo com as deliberações da assembleia geral" (MOÇAMBIQUE, 2010, p. 62).

De acordo com seus estatutos,

O CDM, visando o fomento do desporto de alto rendimento tem por fins: a) $\mathrm{O}$ fomento, prática e o desenvolvimento das diferentes modalidades desportivas nas suas diferentes categorias e escalões; Proporcionar o desenvolvimento desportivo e sócio-cultural dos seus associados (MOÇAMBIQUE, 2010, p. 62).

Neste período de multipartidarismo e de primado da economia de mercado, que deu origem a uma maior competitividade no plano desportivo, começou a história bem menos gloriosa do CDM. O clube foi finalista vencido da taça de Moçambique de 1999. Em 2005, foi despromovido do Campeonato Nacional de Futebol para o campeonato secundário e, em 2006, participou na $2^{\text {a }}$ Liga (Divisão de Honra), tendo-se classificado em $3^{\circ}$ lugar. No ano seguinte ocupou o $2^{\circ}$ lugar (2007). Em 2008, sagrou-se Campeão da II Liga, ascendendo à 1 $1^{\text {a }}$ Divisão Nacional. Entre 2009 e 2011 participou no Campeonato Nacional (Moçambola), tendo-se classificado em $3^{\circ}$ lugar (2009), $7^{\circ}$ lugar (2010) e $12^{\mathrm{a}}$ posição (2011), o que lhe valeu a despromoção para a $2^{\mathrm{a}}$ Liga, onde competiu até 2019.

\section{Histórias de VIDA DOS EX-JOgadores do MATChEdJe de MAPUTO}

Relembremo-lo, os resultados das entrevistas aos ex-jogadores que jogaram entre 1980 e 1990, foram organizados em três temáticas, a saber, (i) infância e adolescência (questões relacionadas com a vivência durante esta faixa etária); (ii) carreira futebolística (questões relacionadas com a atividade de jogadores); (iii) póscarreira futebolística (questões relacionadas com as atividades desenvolvidas depois de terminada a carreira de jogador de futebol). Estes jogadores evoluíram na equipe de Futebol no clube Matchedje entre 1980 e 1990.

\section{INFÂNCIA E ADOLESCÊNCIA}

O sujeito 1 nasceu em Quelimane, Província da Zambézia, no dia 26 de Agosto de 1960, numa família humilde. Iniciou a sua vida estudantil na escola primária Vasco da Gama em Quelimane no início da década 70. As disciplinas que mais gostava eram as Ciências Naturais e a Educação Física. 
Cresceu num ambiente de desportistas, porquanto, na sua infância tinha como brincadeiras o jogar futebol no bairro, a que, nalguns momentos, se juntavam os jogos de basquetebol e voleibol na escola. Relativamente ao futebol, acrescenta "[...] havia falta de escolas de formação de jogadores e começávamos a jogar nos juniores. Joguei no Sporting de Quelimane e posteriormente passei a representar o Ferroviário de Quelimane" (sujeito 1).

O sujeito 2 nasceu no bairro da Maxaquene, em Maputo, em 1961. Em relação à sua infância e adolescência, narra que "[...] cresci como outras crianças jogando futebol porque havia espaços para tal. Usávamos bolas de trapos" (sujeito 2). Fez o ensino primário e secundário.

O sujeito 3 nasceu no bairro do Esturro, na Beira, numa família humilde de 7 irmãos, todos desportistas. Frequentou a escola até ao nível médio, que concluiu na escola secundária Sansão Muthemba. Lembra-se da rivalidade que, na altura, existia entre os bairros. Porque ninguém queria perder, essa rivalidade acabou promovendo muitos talentos de futebol na Beira.

O sujeito 4 nasceu em Maputo, no dia 20 de Dezembro de 1968, filho de pai funcionário público e de mãe camponesa. Segundo de três irmãos, cresceu no bairro da Maxaquene. Fez o ensino primário na escola primária Santo António da Malhangalene. Frequentou o ciclo preparatório na escola secundária da Polana e o ensino secundário nas escolas secundárias Josina Machel e Francisco Manyanga. As suas brincadeiras no bairro eram preenchidas pelas "peladinhas" de futebol e aí se ganhava a paixão pela modalidade.

Das falas dos nossos entrevistados pode-se apurar que tiveram uma infância igual a outras crianças com várias brincadeiras e jogos, tais como zotho ${ }^{19}$, escondidas ${ }^{20}$ e carrinhos de arame. Todos afirmaram terem tido uma paixão pela prática do desporto, destacando-se o futebol como a modalidade de eleição. Apesar de um dos entrevistados ter ingressado nos iniciados de um clube, todos tiveram a rua por cenário de iniciação da prática do futebol, passando da rua para as equipes representativas dos clubes.

\section{CARREIRA FUTEBolística}

O sujeito 1 começou a jogar o futebol oficial nos juniores em Quelimane, nos clubes Sporting e Ferroviário, e muito rapidamente, ainda com idade de júnior, subiu aos seniores. Devido à sua visibilidade, foi recrutado para o Serviço Militar Obrigatório (SMO) e, por via disso, passou a representar o Matchedje de Maputo.

Para além de ter conquistado os títulos de campeão nacional de futebol e de vencedor da taça de Moçambique, como jogador atingiu as quartas-de-final da Taça dos Clubes Campeões de África, atual Liga dos Clubes Campeões de África. Terminou a carreira de jogador em 1990, com 30 anos, de idade devido a uma lesão no joelho.

O sujeito 2 afirmou: "[...] comecei a jogar nas escolas de jogadores do Desportivo em 1973 mas por influência de amigos de infância acabei deixando o clube para a Académica treinado por José Pérides" (sujeito 2). Porque os amigos não conseguiram ficar na Académica, emigraram para o Benfica (atual Costa do Sol) em 1976 e 1977, pelo que o nosso entrevistado novamente seguiu os seus amigos.

\footnotetext{
${ }^{19}$ Zotho é um jogo de perseguição jogado em grupo. Um indivíduo "A" é escolhido para perseguir os/as outros/as. Se conseguir tocar um elemento, este/a o substitui, passando a perseguir os/as outros/as.

${ }^{20}$ Escondidas é um jogo feito em grupo. Um indivíduo "A" é escolhido para começar o jogo. O indivíduo "A" fecha os olhos e grita "bananou" e os demais respondem "aindou" enquanto se escondem. Depois de todos terem se escondido (estes gritam "já comeu!"), o indivíduo "A" abre os olhos e começa a procurar os outros do grupo. Se conseguir encontrar todos, vence o jogo e escolhe-se outro indivíduo para continuar. E se não conseguir encontrar todos, recomeça o jogo.
} 
Com 19 anos, e por ver que o futebol não tinha futuro e por dificuldades da vida, porquanto perdera o pai quando tinha 11 anos, em 1979 foi para a Riopele de Marracuene para trabalhar e jogar futebol recreativo.

Em 1981, os portugueses que trabalhavam na empresa pretendiam levá-lo para Portugal para jogar na Riopele de Portugal, mas, porque a política em Moçambique não o permitia, não emigrou. No mesmo ano, o Costa do Sol quis que ele voltasse para o clube, mas devido ao chamamento para o SMO não foi possível.

Após treinar no quartel de Boane, o Matchedje de Maputo incorporou-o na equipe de futebol em 1982. Lembra que, nessa altura, a equipe era constituída por bons jogadores como Chababe, Nacir, Geraldo Conde, Faruk, Filipe, entre outros, mas conseguiu ser titular. Foi campeão por esta equipe em 1987 e atingiu as quartas-de-final da Taça dos Clubes Campeões de África no ano seguinte. Terminou a carreira por idade no Estrela Vermelha, por empréstimo.

O sujeito 3 iniciou a sua carreira nos juvenis do Ferroviário da Beira, tendo passado pelo Centro Africano e pelo Palmeiras da Beira, antes de ingressar no Matchedje. Conta que "[...] fui incorporado no SMO em 1980 e depois dos treinos militares passei a jogar futebol no Matchedje onde terminei a carreira por idade, 36 anos, para dar lugar aos mais novos" (sujeito 3).

Fez parte da célebre equipe do Matchedje, campeã em 1987 e que atingiu as quartas-de-final da Taça dos Clubes Campeões de África no ano seguinte. Lembra que o Matchedje era equipe do Estado e recebia todo o apoio do Presidente da República, Samora Machel. Termina afirmando que "[...] jogávamos por amor à camisola ${ }^{21 "}$ (sujeito 3).

O sujeito 4 iniciou a sua carreira futebolística em 1983, nos iniciados do Clube Desportivo Estrela Vermelha com 15 anos. Dois anos depois, 1985, ingressou no Clube Desportivo de Matchedje a partir de recrutamento realizado por um oficial superior que o viu a jogar no Clube Estrela Vermelha. Este oficial tratou de prometer oferecer um rancho mensal ${ }^{22}$ para a família do jovem. No entanto, nos primeiros momentos, os pais recearam que o filho fosse para a tropa numa época que havia a guerra civil em Moçambique.

Narra que

[...] ainda na categoria de juvenis realizei jogos nos juniores a convite do mister Kid e sagrei- me campeão da cidade. Em 1986 continuei no mesmo escalão de juniores, mas já era convocado na equipa sénior para fazer jogos de torneio de abertura e do campeonato nacional (sujeito 4).

Em 1987, ascendeu ao escalão máximo no mesmo clube, trabalhando com o treinador Victor Bondareko. Entretanto, no mesmo ano contraiu uma lesão grave nos ligamentos do joelho direito, no Estádio da Machava, no jogo contra o Clube Desportivo de Maputo a contar para o campeonato nacional, no ano em que o clube se sagrou campeão nacional de futebol.

Continuou afirmando que

[...] foi esta lesão grave que me afastou dos relvados definitivamente em virtude de não ter sido tratado devidamente dada a gravidade da mesma (ligamentos no joelho direito). Foram tantas promessas não cumpridas para o tratamento no estrangeiro, lamentavelmente foi assim o fim da minha carreira ainda na flor da idade (20 anos de idade (sujeito 4).

\footnotetext{
${ }^{21}$ Esta frase é usada quando os jogadores são amadores e não recebem salários por jogar futebol.

${ }^{22}$ Numa época que escasseava comida nas lojas moçambicanas.
} 
Quando tudo indicava que teria um futuro promissor no Matchedje, assim como na seleção nacional, terminou nestas circunstâncias a carreira promissora deste jogador, que já tivera uma internacionalização pela seleção nacional de juniores no torneio de COSSAFA, realizado no Malawi, em 1986.

Como não raro sucede no mundo desportivo, nem todos os nossos entrevistados obtiveram os resultados desejados. Na circunstância, pesaram condicionalismos políticos em torno das atividades desportivas. Assim, alguns tinham uma vontade grande de alcançar sucesso no estrangeiro, mas, devido à política vigente nessa altura ${ }^{23}$, não conseguiram emigrar para jogar no estrangeiro.

Das falas dos ex-jogadores do Matchedje em relação à idade do encerramento de suas carreiras podemos verificar-se que se situou entre 20 e 36 anos. Dois jogadores terminaram as carreiras devido à lesão (20 e 30 anos) e outros dois por idade (36 anos), neste caso, em linha com o que se observa no mundo futebolístico.

\section{Pós- CARREIRA FUTEBolístiCA}

Após terminar a carreira, o sujeito 1, disse que teve o apoio do clube e até hoje faz parte dos seus quadros, tendo, como os demais entrevistados, passado à reserva na carreira militar. Fez formação com professor de Educação Física no Instituto Nacional de Educação Física (INEF) e frequentou vários cursos de treinadores de futebol.

Posteriormente licenciou-se em Educação Física e Desporto pela Faculdade de Educação Física, da Universidade Pedagógica. Trabalha nas camadas de formação do clube e já treinou a equipe principal de futebol por várias vezes.

Afirma que a

[...] inserção como profissional após a carreira não foi difícil porque o clube me amparou. Tive apoio a todos os níveis". A terminar recomenda: "a perfeição não tem limites. O corpo dirigente deve se juntar e encontrar plataforma para ultrapassar os problemas que o futebol enfrenta (sujeito 1).

O sujeito 2, ao terminar a carreira abraçou a função de treinador das camadas de formação do Matchedje. E afirma que

[...] os dirigentes devem olhar para a formação dando condições e assistência aos treinadores. Os treinadores de formação não estão a ser pagos como deveria ser. Você fica dono da formação, como pai. [...] Não há motivação para trabalhar nestas camadas. Não há equipamentos, por exemplo, falta de meias, não há transporte. Prefiro dar dinheiro de chapa ao menino e eu ir a pé para casa. Contudo, não desanimamos e continuamos a dar o nosso melhor de modo a fornecer atletas para o clube e selecção nacional (sujeito 2).

Continua dizendo que "[...] se nós queremos ver Moçambique como outros países, é preciso investir e planificar a longo prazo. O futebol requer paciência. Há muitos dirigentes curiosos que não entende nada de futebol" (sujeito 2). Para além de trabalhar nas camadas de formação foi treinador da equipa principal aquando das "chicotadas psicológicas".

\footnotetext{
${ }^{23}$ Não era permitido que jogadores moçambicanos jogassem no estrangeiro.
} 
O sujeito 3 disse que, após terminar a carreira, a sociedade o acolheu bem e não tem queixas. Continua a ter o apoio do clube. Acerca do incremento do futebol, diz "[...] o governo deve dar mais apoio às províncias. Nas províncias há muitos talentos. Também deve dar mais apoio a todos os clubes" (sujeito 3 ).

Após terminar a carreira de futebolista precocemente, o sujeito 4 frequentou o Instituto Nacional de Educação Física (INEF) de 1989 a 1992 e fez o curso de treinadores de futebol. E diz "[...] daí fui indicado para trabalhar nas camadas de formação onde registo o ganho de alguns títulos. No ano de 2005 fui indicado adjunto treinador da equipe sénior do Matchedje que participou no Moçambola" (sujeito 4).

Posteriormente, licenciou-se em Educação Física e Desporto pela Faculdade de Educação Física e Desporto, da Universidade Pedagógica. Tendo passado a trabalhar como professor de Educação Física numa escola secundária, continua como quadro do Ministério da Defesa na área desportiva.

Em alusão aos apoios solicitados e obtidos, os entrevistados afirmaram nunca ter solicitado apoio ao governo, nem às estruturas desportivas, mas receberam apoio do clube, onde dois foram integrados como treinadores dos escalões de formação e o outro, por influência do clube, foi enquadrado numa empresa pública.

Após o termo das carreiras de futebolista, a escolaridade dos ex-jogadores melhorou, porque todos terminaram o ensino secundário. E dois destes fizeram o ensino superior na área de Educação Física e Desporto, em consonância com o que se observa noutros países. A par dos capitais envolvidos nesta atividade, a especialização do saber desportivo proporciona a oportunidade para os ex-futebolistas prosseguirem a sua formação acadêmica acerca da sua profissão.

Não raro, ex-jogadores elevam o seu nível de escolaridade comparativamente ao início da carreira.

Em parte por acréscimo de formação e da consequente capacidade crítica, os que estão envolvidos no treinamento dos escalões de formação afirmam que há falta de apoio por parte do clube e do Estado para preparar em boas condições o jogador do amanhã. Apelam, também, às estruturas do governo para que apoiem a formação dos jogadores e aos clubes para darem mais incentivos aos treinadores e criarem condições para as camadas de formação.

Dos quatro entrevistados nenhum está "nas ruas da amargura", embora não ostentem riqueza nenhuma por não terem acumulado valores monetários significativos, porquanto, na altura, jogavam por "amor à camisola". Os quatro exercem funções distintas sendo dois treinadores, um professor e um funcionário público.

\section{CONSIDERAÇÕES FINAIS}

Deste estudo, constatamos que os nossos entrevistados tiveram uma infância igual a outras crianças com várias brincadeiras e jogos de rua. Todos afirmaram que tiveram paixão pela prática do desporto a partir da escola e bairro, destacando-se o futebol como a modalidade de eleição. Apesar de um dos entrevistados ter ingressado nos iniciados, todos tiveram a rua como cenário de iniciação da prática do futebol, passando da rua para os clubes.

Constatamos que as causas do encerramento da carreira dos ex-futebolistas foram a idade e as lesões, como tem acontecido em outros quadrantes do mundo. No entanto, durante a carreira nem todos os nossos entrevistados obtiveram os resultados desejados. Na circunstância, pesaram condicionalismos políticos que impediam que os 
jogadores pudessem jogar no estrangeiro, mas, devido às normas vigentes nessa altura, não conseguiram emigrar para jogar.

Ao nível de inserção social e profissional dos ex-praticantes de futebol, os entrevistados mostram-se bem integrados nas suas áreas profissionais (treinadores, professor e funcionário público). Os ex-futebolistas preocuparam-se em continuar com os estudos, contribuindo assim para a diminuição de jogadores com escolaridade baixa. Dois deles licenciaram-se em Educação Física.

Percebe-se então que alguns ex-jogadores do Clube Desportivo Matchedje tiveram seu enquadramento no clube como treinadores das camadas de formação. No entanto, dois tiveram o privilégio de treinar a equipe principal de futebol.

Sugere-se uma pesquisa exaustiva com outros ex-jogadores que atuaram em outras equipes de futebol chegando a representar a seleção nacional para podermos avaliar a sua inserção na vida pós-carreira.

\section{REFERÊNCIAS}

AGRESTA, M. C.; BRANDÃO, M. R. F.; BARROS NETO, T. L. de. Impacto do término de carreira desportiva na situação económica e profissional de jogadores de futebol profissional. Revista Brasileira de Ciência e Movimento, v. 16, n. 1 , p. 29-38, 2008a.

AGRESTA, M. C.; BRANDÃO, M. R. F.; BARROS NETO, T. L. Causas e consequências físicas e emocionais do término de carreira desportiva. Revista Brasileira de Medicina do Esporte, v. 14, n. 6, p. 504-508, nov./dez. 2008b.

AMARAL, P. R. T.; THIENGO, C. R.; SILVA OLIVEIRA, F. I. Os motivos que levaram jogadores de futebol amador a abandonarem a carreira de jogador profissional. Lecturas: Educación Física y Deportes, v. 12 , n. 115 , dic. 2007.

BENTO, J. O. Desporto: discurso e substancia. Belo Horizonte: Instituto Casa da Educação Física, UNICAMP - Centro de Estudos Avançados, 2013. (Coleção CEAv Esporte, v. 02).

BRANDÃO, M. R. F. O lado mental do futebol. In: BARROS NETO, T. L.; GUERRA, I. (ed.). Ciência do futebol. Barueri: Manole, 2004. p. 203-220.

DOMINGOS, N. (2006). Futebol e colonialismo, dominação e apropriação: sobre o caso moçambicano. Análise Social, v. 41, n. 179, p. 397-416, 2006.

DOMINGOS, N. Das relações entre escrita e performance: o futebol em Moçambique colonial. Projeto História, n. 49, p. 1- 31, abr. 2014.

GUIMARÃES, A. S. O jogo acabou: um estudo sócio-antropológico sobre o fim da trajetória profissional de atletas do futebol. 2017. 147 f. Tese (Doutorado em Sociologia) - Centro de Ciências Humanas, Letras e Artes, Universidade Federal da Paraíba, João Pessoa, 2017.

KUNZ, M. 256 millones juegan al fútbol. FIFA Magazine, Gran Censo 2006, p. 10-15, jul. 2007.

LEÃO, L. Narrativas e histórias de vida na pesquisa acadêmica: reflexões sobre o método. In: RUBIO, K. (org.). Narrativas biográficas: da busca à construção de um método. São Paulo: Képos, 2016. p. 21-37.

LÜDKE, M.; ANDRÉ, M. Pesquisa em educação: abordagens qualitativas. 2. ed. São Paulo: EPU, 2013. MARCO, G. L.; LUIZ FILHO, J. Causas e efeitos do encerramento da carreira futebolística. Saúde e Meio Ambiente: Revista Interdisciplinar, v. 2, n. 1, p. 59-68, jan./jun. 2013.

MARCONI, M. A.; LAKATOS, E. M. Fundamentos de metodologia científica. 5. ed. São Paulo: Atlas, 2003. 
MOÇAMBIQUE. República de Moçambique. Clube Desportivo Matchedje. Boletim da República, n. 41, $\quad 4^{\circ} \quad$ suplemento, p. 62-68, 19 out. 2010. Disponível em: https://www.presidencia.gov.mz/por/Informacao/Imprensa/Boletins-da-Republica/Boletins-da-Republica2010/BR-N.1-41-III-SERIE-2010. Acesso em: 23 ago. 2021

PINEAU, G. Experiências de aprendizagem e histórias de vida. In: CARRÉ, P.; CASPAR, P. Tratado das ciências e das técnicas da formação. Lisboa: Instituto Piaget, 1999. p. 37-50.

RUBIO, K. Memórias e narrativas biográficas de atletas olímpicos brasileiros. In: RUBIO, K. (org.). Preservação da memória: a responsabilidade social dos Jogos Olímpicos. São Paulo: Kepós, 2014. p. 105-121.

RUNGO, M. Inserção social dos ex-futebolistas após o término da carreira, na Cidade de Maputo. 2014. Monografia (Licenciatura em Gestão do Desporto) - Faculdade de Educação Física e Desporto, Universidade Pedagógica, Maputo, Moçambique, 2014.

Recebido em: 23 ago. 2021. Aprovado em: 12 set. 2021. 